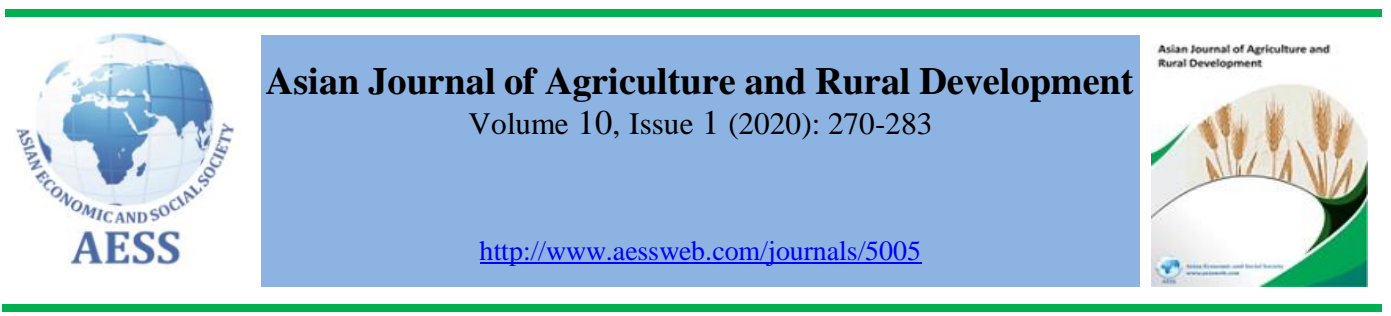

\title{
EXPLORING HETEROGENEITY IN SHRIMP FARMERS' PREFERENCES FOR THE CONTRACTS OF PRODUCING CERTIFIED ORGANIC SHRIMP
}

\begin{abstract}
Duyen Thi Thu Tran ${ }^{\mathrm{a}, \mathrm{b}}$ Yoshifumi Takahashi ${ }^{\mathrm{c}}$

Hisako Nomura ${ }^{c}$

Mitsuyasu Yabe ${ }^{c}$
\end{abstract}

\section{ARTICLE HISTORY: \\ Received: 06-Feb-2020 \\ Accepted: 22-Apr-2020 \\ Online Available: 18-May- 2020 \\ Keywords: \\ Certified organic shrimp, Farmers' stated preference, Choice experiments, Contract design, Heterogeneous preferences}

a Graduate School of Bioresource and Bioenvironmental Sciences, Kyushu University, Fukuoka, Japan

b College of Economics, Can Tho University, Can Tho City, Vietnam

${ }^{c}$ Faculty of Agriculture, Kyushu University, Fukuoka, Japan

- $\square$ thuduyen@ctu.edu.vn (Corresponding author)

\section{Contribution/ Originality}

This study contributes to the literature about farmers' preferences for adopting the environmentally friendly practice, especially in the field of aquaculture, by analyzing shrimp farmers' preferences for the contract of producing certified organic shrimp. This study also provides useful information for processing companies and the (local) government to expand this environmentally friendly practice.

DOI: 10.18488/journal.1005/2020.10.1/1005.1.270.283

ISSN (P): 2304-1455/ISSN (E):2224-4433

How to cite: Duyen Thi Thu Tran, Yoshifumi Takahashi, Hisako Nomura, and Mitsuyasu Yabe (2020). Exploring heterogeneity in shrimp farmers' preferences for the contracts of producing certified organic shrimp. Asian Journal of Agriculture and Rural Development, 10(1), 270-283.

(C) 2020 Asian Economic and Social Society. All rights reserved. 


\section{INTRODUCTION}

The increasing demand of consumers on safe, quality-rich and environmentally friendly food, which accompanies the establishment of associated standards, created market barriers, on one hand, new opportunities for the aquaculture supply chain on the other hand. To satisfy consumer demands, the aquaculture industry has been changing its pattern and restructuring its supply chain to meet such standards. Especially, improving vertical coordination in the supply chain is very important to ensure the stable supply of quality products.

Contract farming is the most widely used method of vertical coordination (Rehber, 2007). To take the advantages of adopting standards and supplying the certified products such as better market access, improving competitiveness, and increasing customer trust (Trifković, 2014), processing companies integrate farmers into the value chain through the contract to have a stable supply source of such products. To attract farmers to participate in the contract of producing such products, the company should build reasonable contracts which provide proper benefit for farmers to adopt this sustainable practice over other alternatives. To build reasonable contracts, analysis of farmers' preferences for the contract's attributes is an important step. Successful build and implementation of the contracts not only tighter cooperation between the company and farmers to supply such quality products for the consumers, but also improve economic outcomes for the producers.

Recently, to support policy-makers to build good contract from the farmers' point of view, choice experiment (CE) method has been used to explore farmers' preferences for the contracts(Abebe et al., 2013; Blandon et al., 2009; Broch et al., 2013; Christensen et al., 2011; Espinosa-Goded et al., 2010; Gelaw et al., 2016; Lemeilleur et al., 2020; Ochieng et al., 2017; Schipmann and Qaim, 2011; Van den Broeck et al., 2017; Vassalos et al., 2016; Villanueva et al., 2017). However, there are limited studies research on the contract focusing on sustainable certification. To our knowledge, the are two studies applied CE to explore farmers' preferences for fair-trade contracting in Benin (Van den Broeck et al., 2017) and eco-certified contract for coffee products in Brazil (Lemeilleur et al., 2020). Moreover, no study applied CE to analyse farmers' preferences for contracts of producing quality and environmentally friendly products in the field of aquaculture. Filling this gap, in this research we apply CE to explore farmers' preferences for the contract of producing certified organic shrimp in Vietnam.

Vietnam is one of the largest producers and exporters of shrimp in the world (FAO, 2019). Recently, to prevent the degradation of mangrove forest and mangroves' ecosystem services due to the expansion and intensification of the shrimp culture system, the Vietnamese government has promoted a model of integrated mangrove-shrimp culture. This is a special kind of extensive shrimp culture model, which is mainly dependent on ecological services supplied by nature, and especially maintains a certain proportion of mangroves in the shrimp farms according to local regulations. However, this policy of protecting forests through regulations has some disadvantages such as lack of economic incentives for forest conservation. Thus, together with this regulation, a potential solution for mangroves' protection through economic mechanism has been implemented recently. In 2000, a certified organic shrimp production project was started in the Ca Mau province to preserve the mangroves and promote responsible aquaculture production through the certification of organic shrimp (GIZ, 2014). The first project, established by the Vietnam Association of Seafood Exporters and Producers and Ca Mau Department of Fisheries, is funded by the Swiss Import Promotion Program (SIPPO). Organic shrimp are cultured following Naturland standards, certified by the Institute for Market Ecology, Switzerland, and bought by the Ca Mau Frozen Seafood Processing Import Export Corporation (CAMIMEX) for export to Switzerland. In 2009, a second project was implemented also funded by SIPPO. In this project, certified organic shrimp are purchased and export by Nam Can Sea-product Import Export Join Stock Company (SEANAMICO) (Ha et al., 2012). In 2013, the International Union for the Conservation of Nature 
and the Netherlands Development Organization started a third project, funded by BMUB, the German Ministry of Environment, Natural Resources, Building, and Nuclear Safety (IUCN, 2016). In this project, Minh Phu Seafood Corporation buys and exports certified organic shrimp. Being certified as organic shrimp farmers, they can receive a premium price for their products. However, this benefit is judged to be inconsistent with the contribution of people in the supply chain of quality products. After export, the price premium of the organic shrimp-the price is $20 \%$ higher than that of normal shrimp- is distributed along the value chain. Farmers were paid $5 \%$ and $15 \%$ premium by CAMIMEX and SENAMICO respectively. However, farm-gate prices of certified organic shrimp paid by the companies were lower than the prices of non-certified shrimp; this was applied to discourage mixing no-certified with certified organic shrimp. Thus, farmers received "the same (or a little more) from certified organic shrimp compared to non-certified products" (Ha et al., 2012). Also, farmers had to wait several months to receive the premium. Because of these problems, many farmers withdrew from the program (Ha et al., 2012). In the third project, farmers are directly paid 3,000 VND/kg (0.13 USD/kg - approximately $1 \%$ of the shrimp price) as the price premium per kilogram of organic shrimp by the Minh Phu Seafood Corporation. In addition, farmers also received 500,000 VND for owning one hectare of mangrove and buy quality shrimp seed at a lower price from Minh Phu Seafood Corporation. In total, the added value for shrimp is $2.5 \%$ of the shrimp price (IUCN, 2016). Although there are certain problems in benefit-sharing mechanisms, certified organic shrimp production projects are beneficial to a part of shrimp farmers and contribute to the protection of mangrove forests and mangrove ecosystems. Thus, this sustainable practice is encouraged to be expanded to other coastal provinces.

To successfully carry out the project expanded to other localities, it is important to pay attention to building a suitable contract with appropriate distribution of benefits for farmers to attract their participation and long-term cooperation with the company. Therefore, this paper makes an ex-ante evaluation of farmers' preferences for contracts with a processing company to produce certified organic shrimp. The findings of the paper will provide useful information for the company to design reasonable contracts as well as for the (local) government to create a better institutional environment for promoting this sustainable production model.

\section{MATERIALS AND METHODS}

\subsection{Study area and data collection}

This study was carried out in the Vietnamese part of the Mekong Delta, which is located in the southern part of Vietnam. With an area of approximately 40,000 square kilometers, the Vietnamese Mekong Delta is the largest shrimp production region in the whole country. In 2016, the shrimp yield of this region was 535,522 tons, accounting for $82 \%$ of the county's total (General statistics office of Vietnam, 2016). Mekong Delta also has the largest remaining mangrove forests in Vietnam, accounting for 70\% of Vietnam's total. Among the 14 provinces in the Mekong Delta, Ca Mau has the largest mangrove forest area, followed by Tra Vinh (Tran and Ha, 2008). The certified organic shrimp projects have been implemented in $\mathrm{Ca}$ Mau province. To serve the plan of expanding the project to other coastal provinces, Tra Vinh province is selected to survey farmers' preferences for the contract of producing certified organic shrimp. 220 integrated mangrove-shrimp farmers were face-to-face interviews from August to September in 2017. Of these 220 farmers, 121 farmers $(55.00 \%)$ intend to adopt certified organic shrimp practice; thus these 121 farmers were asked their preference for the hypothetical contract of producing certified organic shrimp. However, one respondent could understand and answer CE question because of low education. Thus, 120 respondents' responses to CE questions were analysed. 


\subsection{Choice experiments}

CE was initially developed by Louviere and Hensher (1982) and Louviere and Woodworth (1983). It has been widely applied in many disciplines such as transportation, marketing, and environmental economics.

In this paper, we apply this method to explore farmers' preferences for hypothetical contracts to adopt certified organic shrimp production.

Suppose farmer $i$ has preferences for a set of $K$ alternative contracts. Each contract is described as a bundle of attributes and attributes' levels.

The farmer's utility derived from contract $j$ is $U_{i j}$ and can be divided into two components: deterministic component $V_{i j}$ and error component $e_{i j}$ :

$$
U_{i j}=V_{i j}+\varepsilon_{i j}
$$

Farmer evaluates each contract by its utility, compares them and then chooses the one with maximum utility. Hence the probability of the farmer choosing contract $j$ is equal to the probability that the utility of contract $j$ is greater than (or equal to) the utility of contract $k$ :

$P_{i j}=P\left[\left(V_{i j}+\varepsilon_{i j}\right) \geq\left(V_{i k}+\varepsilon_{i k}\right)\right] \forall k \in k=1, \ldots, K ; j \neq k$

Rearrange above equation:

$P_{i j}=P\left[\left(\varepsilon_{i k}-\varepsilon_{i j}\right) \leq\left(V_{i j}-V_{i k}\right)\right] \forall k \in k=1, \ldots, K ; j \neq k$

The error terms are assumed to be independently and identically distributed and follow a Type 1 extreme value distribution.

Under these assumptions, the probability of the farmer choosing contract $j$ out of the set of $K$ contracts is estimated with Conditional Logit Model (CL):

$P_{i j}=\frac{\exp V_{i j}}{\sum_{k=1}^{K} \exp V_{i k}}=\frac{\exp \left(\beta_{i}^{\prime} x_{i j}\right)}{\sum_{k=1}^{K} \exp \left(\beta_{i}^{\prime} x_{i k}\right)} ; k=1, \ldots, j, \ldots K ; j \neq k$

Where $x_{i j}$ are observed variables that related to the alternative and farmer, $\beta_{i}$ is a vector of coefficients of these variables for farmer $i$. This model requires the satisfaction of "Independence from Irrelevant Alternatives" (IIA) assumption.

Mixed logit (ML) is an advanced model that relaxes the assumption of IIA, allow for random taste variation and correlation in unobserved factors over time (Train, 2002). According to the author, the formula of ML model is expressed as follows,

$P_{i j}=\int\left(\frac{\exp \left(\beta^{\prime} x_{i j}\right)}{\sum_{k=1}^{K} \exp \left(\beta^{\prime} x_{i k}\right)}\right) f(\beta) d \beta ; k=1, \ldots, j, \ldots K ; j \neq k$

In this model, $\beta$ varies over farmers in the population with density $f(\beta)$. Therefore, it can reveal the preference heterogeneity among respondents from the analysed results.

ML can be also used to estimate individual-level parameters (Train, 2002). The mean $\beta$ in the subpopulation of people who would choose $j$ when facing choice alternatives described by $x$ is 
$\bar{\beta}=\frac{\int \beta \cdot P(j \mid x, \beta) f(\beta \mid \theta) d \beta}{\int P(j \mid x, \beta) f(\beta \mid \theta) d \beta}$

where $P(j \mid x, \beta)$ is the probability of $j$ conditional on knowing $\beta$

$\bar{\beta}$ can be estimated through simulation (Train, 2002). This procedure includes taking draws of $\beta$ from the population density $f(\beta \mid \theta)$ and then calculating the weighted average of these draws. The simulated subpopulation mean is

$\check{\beta}=\sum_{r} w^{r} \beta^{r}$

where

$$
w^{r}=\frac{P\left(j \mid x, \beta^{r}\right)}{\sum_{r} P\left(j \mid x, \beta^{r}\right)}
$$

\subsection{Willingness to pay/willingness to accept}

Willingness to pay (WTP) or Willingness to accept (WTA) is obtained as the ratio of an attribute parameter to the monetary parameter - the premium parameter in this paper.

$W T A=-\frac{\widehat{\beta}_{\text {attribute }}}{\widehat{\hat{\beta}}_{\text {premium }}}$

The above formula is used to estimate WTP/WTA in CL and ML1. In ML1, the coefficients of all attributes are treated as random coefficients and normally distributed, except the premium. Treating the coefficient of premium as a fixed coefficient has some advantages such as the coefficient has the right sign and the distribution of WTP/WTA for the attributes has the same distribution of the attribute coefficients (Hole, 2008).

However, significant preference heterogeneity in terms of cost should not be ignored. In ML2, the premium is treated as a random coefficient and has a normal distribution. In this case, there are two alternative practices in deriving WTP/WTA (Hensher et al., 2006). The first one is that WTP/WTA can be estimated through simulation. This procedure involves taking the ratio of an attribute parameter and the price parameter which are drawn from the estimated population distribution, repeating this for many draws to obtain an average WTP/WTA. The second one is the estimation of WTP/WTA from an individual-based parameter. An Individual's WTP/WTA is calculated by taking the ratio of the conditional mean of an attribute parameter to the conditional mean of the cost parameter (of that individual). Hensher et al. (2006) conclude that the second practice provides a lower variance of WTP than the first practice and it hence reduces the unreasonable WTP. Besides, Grisolia and Willis (2011) use this practice and confirm its advantages such as allowing to address heterogeneity in the sample and overcoming the problems of interval estimation. Therefore, the second practice is adopted in this paper to calculate WTP/WTA.

\subsection{Design of the choice experiments}

The important attributes of contracts (Table 1) were decided after carefully evaluating the reports and related studies on the implementation of the Naturland organic shrimp production project in $\mathrm{Ca}$ Mau province, discussing with experts and making a pilot survey. The chosen attributes for the contract alternatives include:

Price premium: This is an important factor that affects farmers' utility when they consider choosing a contract. Farmers prefer contract schemes that offer a higher selling price or price premium (Gelaw et al., 2016; Lemeilleur et al., 2020; Ochieng et al., 2017; Schipmann and Qaim, 2011; Van den Broeck et al., 2017). In our case study, if signing a contract to produce certified organic shrimp, farmers have to comply with the standards of producing organic products. Therefore, a 
proper premium should be used as compensation for farmers' compliance. We suggest four levels of premia to explore farmers' preferences; these were: 3,000; 10,000; 20,000; and 30,000 VND/kg (this works out to $0.13 ; 0.43 ; 0.86$; and $1.29 \mathrm{USD} / \mathrm{kg}$ and is approximately $1 \%, 3 \%, 7 \%$, and $10 \%$, respectively, of the average price of normal shrimp). The lowest level is equal to the current premium of certified organic shrimp paid by a company in Ca Mau province. We expected that a higher premium would increase the farmers' utility and the probability of choosing the contract alternative.

Premium-payment delay: payment delay is one of the problems of contract farming (Glover, 1987; Singh, 2002). This is perceived to be a source of risk for small-scale farmers, and hence decreases their utility and probability of contracting (Blandon et al., 2009; Ochieng et al., 2017). In Ca Mau, certified organic shrimp farmers received premium after selling their shrimp from three to four months because of the delay in exporting shrimp to Europe and late payment of downstream actors in the chain (Ha et al., 2012). While the price premium may increase farmers' utility, the delay in paying it may lose farmers' utility. Therefore, this factor is considered as an attribute in a designed contract to evaluate farmers' preferences. We expected that farmers prefer to receive the premium as soon as possible.

Selling place: Transportation cost is one of the main considerations when farmers choose the selling place for their products. Farmers prefer to sell their products at the farm gate rather than transport them to the market because of the transportation cost (Blandon et al., 2009; Ochieng et al., 2017). In this study, we chose two levels for this attribute, at the farm or company, and expected that farmers prefer selling at the farm. Also, we want to estimate the appropriate compensation for farmers to transport their shrimp to sell at the company because there are some advantages of selling at the company. First, farmers could receive a higher premium. Currently, in $\mathrm{Ca} \mathrm{Mau}$, the collectors who buy certified organic shrimp also receive a commission from the company. If farmers sell shrimp directly to the company, the commission could be transfer to shrimp farmers. Second, excluding small collectors in the value chain could reduce the number of steps of storing shrimp with ice; this keeps the good quality of shrimp.

Seed provision: Besides the premium, the provision of quality seed is a significant benefit of contracting. The provision of quality seed, an important input, as a part of the farming contract increases the probability of farmers' participation in the farming contract (Abebe et al., 2013; Schipmann and Qaim, 2011; Van den Broeck et al., 2017). Because shrimp production is a highrisk farming activity, quality seed which has a high survivor rate and strong resistance of disease is a major consideration of shrimp farmers. Moreover, joining in the certified organic shrimp production project requires farmers to use quality seed. There are 2 levels of these attributes, including seed provision by the company and no seed provision (farmers buy seed by themselves). We expected that farmers prefer seed provision from the company.

Table 1: Description of the contract attributes

\begin{tabular}{llc}
\hline Attribute & \multicolumn{1}{c}{ Description } & \multicolumn{1}{c}{ Levels } \\
\hline $\begin{array}{l}\text { Premium-payment } \\
\text { delay }\end{array}$ & $\begin{array}{l}\text { The farmers will receive premium immediately, } \\
\text { three-month delay, or six-month delay }\end{array}$ & $\begin{array}{c}\text { 3 levels: } 0,3 \text { or } 6 \\
\text { month(s) }\end{array}$ \\
Selling place & $\begin{array}{l}\text { The farmers will sell their products for the } \\
\text { company at their farm (through collectors), or } \\
\text { bring their products to the company to sell }\end{array}$ & $\begin{array}{c}\text { 2 levels: at farm, } \\
\text { at company }\end{array}$ \\
Seed provision & $\begin{array}{l}\text { The company will sell quality seed } \\
\text { to farmers }\end{array}$ & 2 levels: no, yes \\
Premium & $\begin{array}{l}\text { The price premium (per kilogram) of organic } \\
\text { shrimp compared to normal shrimp }\end{array}$ & $\begin{array}{l}4 \text { levels: } 3,000 ; 10,000 ; \\
20,000 ; 30,000 \mathrm{VND} / \mathrm{kg}\end{array}$ \\
\hline
\end{tabular}

Note: 1 USD $=23,271$ VND (date: February $6^{\text {th }}, 2020$ ) 
In this study, we just focus on the contract's attributes which can be negotiated by farmers, not consider the attribute related to the standards of producing certified organic shrimp. Also, certification cost represents the transaction cost of the contract and has a negative impact on growers' utility (Vassalos et al., 2016), however, we do not consider this cost as a contract attribute in our study because it is now supported by the Non-Governmental Organization.

The combination of all attributes and attribute levels is 48 choice sets. A fractional factorial design was used to reduce the choice sets (Hensher et al., 2005), and finally, 16 choice sets were chosen in the questionnaire. The 16 choice sets were blocked into four segments, so each respondent received four choice sets. Each choice set had 3 options including 2 contract alternatives and status quo options (no-contract). An example of a choice set is shown in figure 1.

\begin{tabular}{|l|c|c|c|}
\hline Attribute & Contract A & Contract B & No contract \\
\hline $\begin{array}{l}\text { Premium-payment } \\
\text { delay }\end{array}$ & No delay & $\begin{array}{c}\text { Delay } \\
3 \text { months }\end{array}$ & \\
\hline Selling place & At farm & At company & $\begin{array}{c}\text { I would not } \\
\text { choose } \\
\text { either of } \\
\text { two } \\
\text { contract A, } \\
\text { B }\end{array}$ \\
\cline { 1 - 2 } & No & Yes & \\
\hline Quality seed provision & $10.000 \mathrm{VND}$ & $20.000 \mathrm{VND}$ & \\
\hline Premium & & & \\
\hline My choice & & & \\
\hline
\end{tabular}

Figure 1: Example of a choice set

\section{RESULTS AND DISCUSSION}

\subsection{Farmers' preferences for the contract's attributes}

Table 2 presents the socio-economic description of the surveyed shrimp farmers. The average age of farmers is $50.283 \pm 10.593$ years and $20 \%$ of them are female. The average of farmers' education is $7.067 \pm 3.225$ year, with nearly half of them at the secondary level.

Table 2: Socio-economic characteristics of respondents

\begin{tabular}{lccc}
\hline Characteristic & Mean & $\begin{array}{c}\text { Standard } \\
\text { deviation }\end{array}$ & Percentage \\
\hline Age (years) & 50.283 & 10.593 & 20.0 \\
$\begin{array}{l}\text { Female } \\
\text { Education (years) }\end{array} \quad$ Not attend any schools & 7.067 & 3.225 & 3.3 \\
$\quad$ & & & 26.7 \\
$\quad$ Elementary & & & 47.5 \\
$\quad$ Secondary & & & 21.7 \\
$\quad$ High school & & 0.8 \\
$\quad$ Bachelor & 120 & & \\
Total respondents & & & \\
\hline
\end{tabular}

Source: Authors' estimates 
We used both CL and ML (ML1 and ML2) to analyse the data and then compare the results. The descriptive statistic of the independent variables used in the CL and ML models are shown in Table 3. In ML1, we treat the coefficients of $3 M$ delay, $6 M$ delay, Selling place, and Seed provision as random coefficients with the assumption that they are normally distributed, and the coefficient of Premium as a fixed coefficient. In ML2, the coefficients of all variables are treated as random coefficients and normally distributed.

Table 3: Descriptive statistics of the independent variables used in the CL and ML models

\begin{tabular}{ll}
\hline Variables & \multicolumn{1}{c}{ Description } \\
\hline $3 M$ delay & 1 if a three-month delay in paying a premium; 0 otherwise \\
6M delay & 1 if six-month delay in paying premium; 0 otherwise \\
Selling place & 1 if selling at the company; 0 if at the farm \\
Seed provision & 1 if the company sells quality seed to farmers; 0 if not \\
Premium & Price premium $(1,000$ VND $/ \mathrm{kg})$ \\
ASC & Alternative Specific Constant \\
\hline
\end{tabular}

Based on the estimated results (Table 4), the ML model is preferred to the CL model in terms of its higher value of the log-likelihood function, and lower value of AIC and BIC. Because the superior of the ML model is demonstrated, we focus our interpretation on the results of the ML models. All the coefficients of the models are statistically significant and have the expected sign.

Premium: The coefficient of Premium is positive, indicating that the contracts with a higher premium increase farmers' utility and the probability of choosing a contract. This result supports the findings of previous researches (Gelaw et al., 2016; Lemeilleur et al., 2020; Ochieng et al., 2017; Schipmann and Qaim, 2011; Van den Broeck et al., 2017).

Premium-payment delay: $3 M$ delay and $6 M$ delay reduce farmers' utility and increase their probability of not participating in the contract. This result is in line with Blandon et al. (2009) and Ochieng et al. (2017), who argued that payment delay decreases the probability of contracting.

Selling place: A majority of farmers prefer to sell shrimp at the farm. This finding is in line with the findings of previous researches (Blandon et al., 2009; Ochieng et al., 2017). This could be explained as follows. First, for the integrated mangrove-shrimp culture model, farmers harvest shrimp many times per crop. They harvest shrimp nearly every tide (two tides per month), with several days per tide. Because the shrimp quantity harvested per day is low, farmers prefer to sell shrimp at the farm for convenience. Second, bringing shrimp to the company causes transportation cost and time cost.

Seed provision: The coefficient of Seed provision is positive, indicating that the contracts with the provision of quality seed increase farmers' utility and the probability of choosing a contract. This result is in line with the findings of previous researches (Abebe et al., 2013; Schipmann and Qaim, 2011; Van den Broeck et al., 2017). Moreover, seed provision is more important in the case of low premium and the negative effect of premium-payment delay on farmer's utility. 
Table 4: Estimated results of CL and ML models

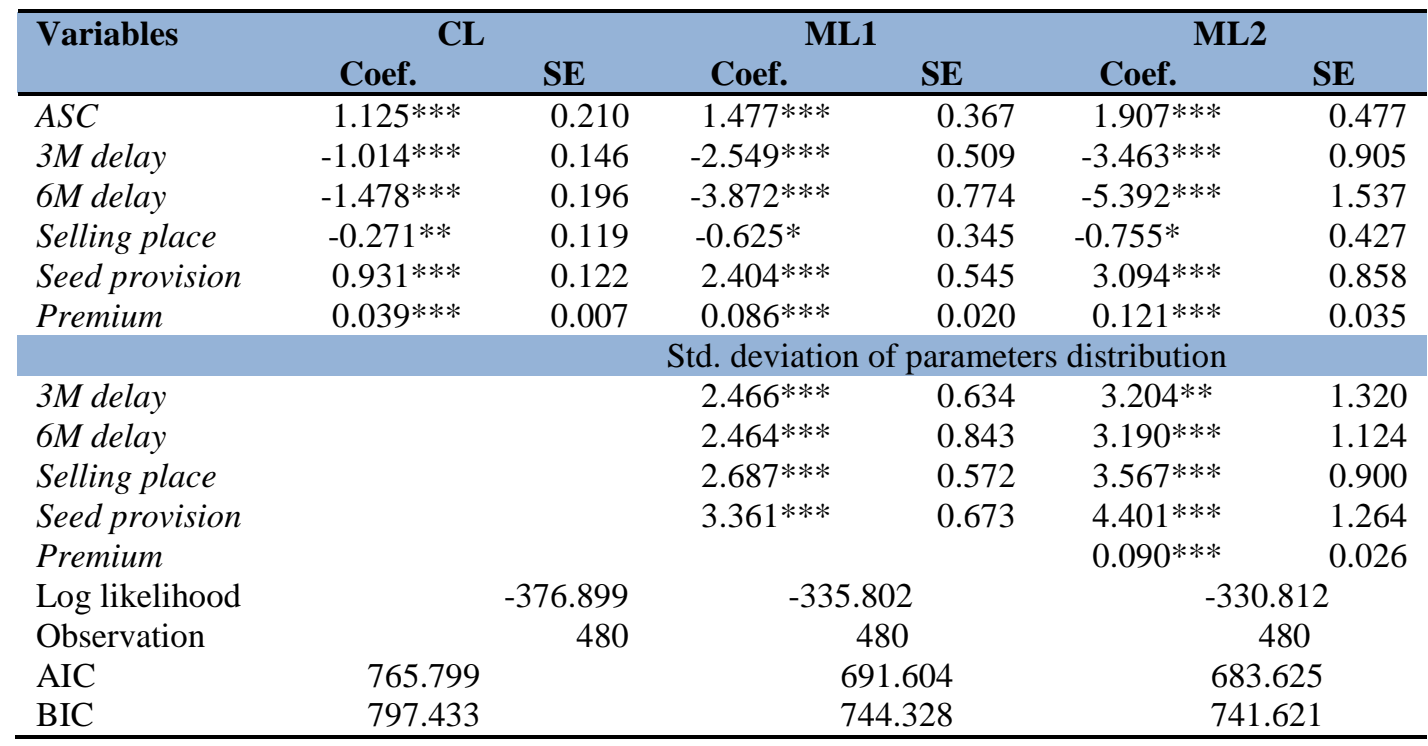

Source: Authors' estimates

$* * *, * *$, and $*$ indicate significance level at $1 \%, 5 \%$, and $10 \%$ levels, respectively

Standard deviations of all the random coefficients in ML1 and ML2 are statistically significant, suggesting the presence of preference heterogeneity among respondents around the mean. Moreover, the estimated means and standard deviations of these coefficients also provide information on the proportion of farmers that places a positive value and negative value on the attributes (Train, 2002). Based on the estimated means (-2.549) and standard deviations (2.466) of the coefficient of $3 M$ delay in ML1, we can know that 84.9 percent of the distribution of this coefficient is below zero and 15.1 percent above. This implies that 84.9 percent of farmers prefer immediate payment, while the other 15.1 percent accept the delayed payment. A similar calculation for $6 M$ delay, 94.2 percent of farmers prefers immediate payment, while the other 5.8 percent accept the delayed payment. 59.2 percent of farmers are estimated to prefer to sell shrimp at the farm, while the other 40.8 want to sell shrimp at the company. 76.3 percent of farmers prefer seed provision, while the other 23.7 percent did not. These estimated numbers are very similar to those in ML2. The standard deviation of the coefficient of Premium in ML2 is statistically significant, suggesting the presence of heterogeneity in farmers' preferences for this attribute. A majority of farmers prefer higher premiums while a small part of farmers can accept the low premium. This can be explained that maybe premium is not the most important factor for some farmers to join in the contract of producing certified organic shrimp. They maybe care more other benefits such as the provision of quality seed and the technical assistants. Because ML2 reflects the heterogeneity in farmers' preferences for premium, it is preferred to ML1. ML2 is also better than ML1 in terms of the log-likelihood, AIC and BIC.

\subsection{Willingness to accept for contract's attributes}

The willingness to accept the contract attributes and the 95\% confident interval of WTA are shown in Table 5. WTA in ML1 and ML2 are slightly higher than CL. Because ML1 and ML2 are better than CL, the WTA results in ML1 and ML2 are chosen to interpret. In ML2, individual parameters are issued to calculate WTA in the sample. Follow Grisolia and Willis (2011), we dropped one respondent, whose coefficient of the premium is close to zero, to obtain a more reliable distribution of WTA [because a price coefficient close to zero would generate unreasonable WTA (Grisolia and Willis, 2011)]. The distribution of WTA for all attributes is shown in figure 2. It is clear from the 
figure that there is heterogeneity in WTA for the attributes, including some farmers willing to pay much and less than the average.

Table 5: Willingness to accept for each contract attribute

Unit: $1,000 \mathrm{VND} / \mathrm{kg}$

\begin{tabular}{lccc}
\hline \multicolumn{1}{c}{ Variables } & CL $^{\mathbf{a}}$ & WTA (95\% Confidence Interval) & ML2 \\
\hline \multirow{2}{*}{ 3M delay } & 25.754 & 29.609 & 31.031 \\
& $(15.298 ; 36.211)$ & $(16.494 ; 42.725)$ & $(-8.494 ; 92.881)$ \\
6M delay & 37.516 & 44.977 & 46.295 \\
& $(22.124 ; 52.909)$ & $(25.273 ; 64.681)$ & $(9.876 ; 133.633)$ \\
Selling place & 6.868 & 7.264 & 7.844 \\
& $(0.593 ; 13.144)$ & $(-0.859 ; 15.388)$ & $(-28.556 ; 69.083)$ \\
Seed provision & -23.646 & -27.923 & -29.616 \\
& $(-33.582 ;-13.712)$ & $(-41.386 ;-14.461)$ & $(-115.533 ; 27.633)$ \\
\hline
\end{tabular}

Source: Authors' estimates

Note: ${ }^{a}$ Confident Interval is calculated by Delta method
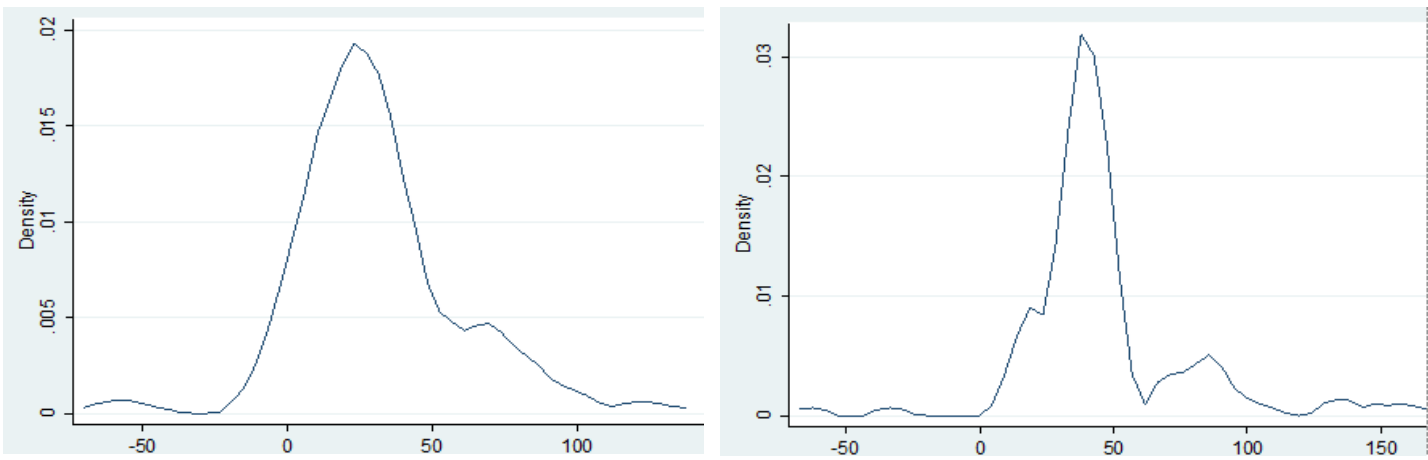

WTA for three-month delay in paying premium

WTA for six-month delay in paying premium
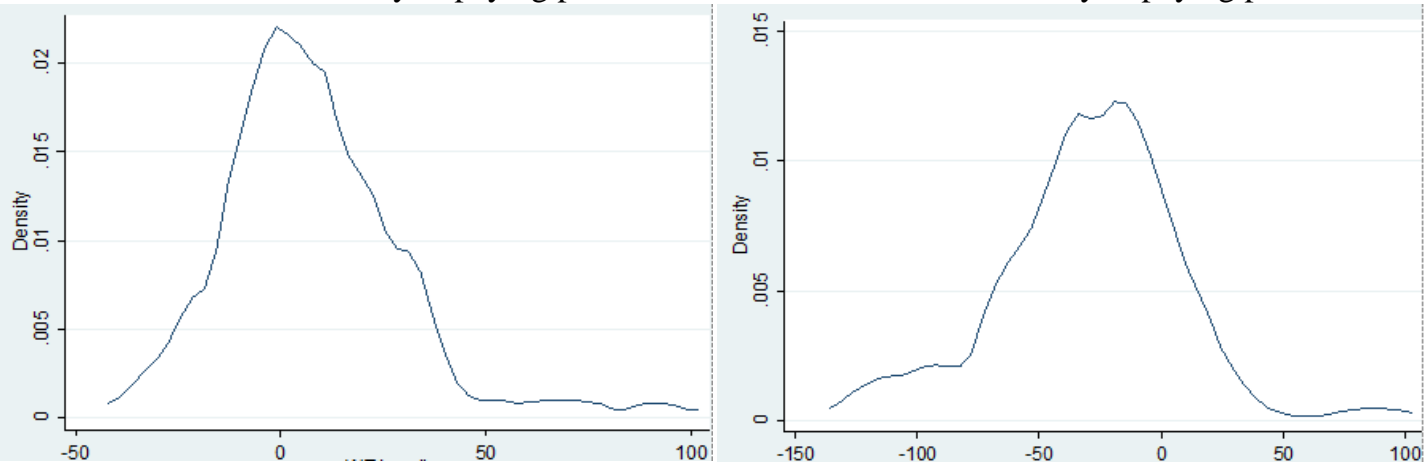

WTA for selling shrimp at the company

WTA to receive quality seed from the company

Figure 2: Distribution of WTA

Premium-payment delay: Table 5 shows that farmers need to receive (on average) 29,609 and $31,031 \mathrm{VND} / \mathrm{kg}$ higher for certified organic shrimp price to compensate for the utility loss associated with $3 M$ delay in paying a premium in the ML1 and ML2 respectively. The research results also show the heterogeneity in farmers' preferences and WTA for this delay (Figure 2). A small part of farmers strongly hates the delay and wants a much higher compensation, while some others can accept the delay of about 3 months. If the premium-payment delay is 6 months, farmers need to receive 44,977 and 46,295 VND/kg higher for certified organic shrimp price in the ML1 and ML2 respectively. The results also show the heterogeneity in farmers' preferences and WTA 
for $6 M$ delay, including some farmers who strongly hate the delay also have very high WTA for it. These farmers can easily refuse to join the contract due to this payment delay. Thus the premium should be paid as soon as possible to attract more farmers to participate in the contract. If the company cannot pay the premium immediately, the delayed payment should be within 3 months. This is because the quality seed provision could help to compensate for the loss of farmers' utility caused by the delay (WTP for seed provision is nearly equal WTA for a three-month delay in paying the premium), even with the lowest premium level (suppose selling shrimp at the farm). However, if the delay is above three months, the quality seed provision could not compensate for the loss of farmers' utility due to the delay. WTA for the six-month delay is $15,000 \mathrm{VND} / \mathrm{kg}$ higher than WTA for the 3-month delay; this means that $5,000 \mathrm{VND} / \mathrm{kg}$ is the average WTA for the onemonth delay (after the third month of the delay). Thus after the third month of the delay, the company should increase 5,000 VND/kg of certified organic shrimp per one-month delay.

Selling place: The price of organic shrimp should be increased 7,264 and 7,844 VND/kg to encourage farmers to transport their products to sell at the company in the ML1 and ML2 respectively. The farmers' WTA for selling shrimp at the company are also heterogeneous. This heterogeneity occurs due to the different location of shrimp farms that leads to the differences in transportation cost and time cost, even some farms located in a remote area with bad road condition. In this situation, farmers should cooperate through farmers' group or cooperative to together transport shrimp to the company. This may help to reduce transportation costs with a big amount of shrimp to be transported to the company. Besides, cooperative can help to protect farmers' benefits from joining in the contract of producing certified organic shrimp. The establish of farmers' group or cooperative should be discussed more in future researches. For farmers who have farms in remote areas and cannot directly bring shrimp to the company, the company can help them reduce the distance, time and cost of transportation by laying some collection points in these areas. In these ways, certified organic shrimp can be transferred from farmers to the company without small collectors. This can help to keep the better quality of certified organic shrimp because of reducing the number of steps of storing shrimp with ice.

Seed provision: Farmers are willing to accept the lower price of certified organic shrimp at an average of 27,923 and $29,616 \mathrm{VND} / \mathrm{kg}$ to receive the quality seed in the ML1 and ML2 respectively; this is the farmers' willingness to pay to receive the quality seed from the company instead of buying seed by themselves. The results also show the heterogeneity in farmers' preferences and WTA for Seed provision, including some farmers are willing to pay a very high amount to receive quality seed from the company. This indicates that the provision of quality seed is very important for them because it can help to improve the productivity of shrimp production and thus increase shrimp farm's profit. This also explains why some farmers do not care much about the level of premium because high productivity may affect profits much higher than the premium. However, a small part of farmers wants to choose the shrimp seed by themselves. Due to the heterogeneity in farmers' preferences for seed provision, the company can make flexible contracts with farmers according to their preferences. The company should provide quality seed for the section of farmers who need it while letting the other section freely buy seed as long as its quality is good.

Finally, as mentioned, we did not consider the certification cost as a contract attribute to analyze farmers' preference for it. In the future, if the NGOs do not support this cost any more, it will become a significant barrier of contracting to produce certified organic shrimp. This should be carefully assessed in future researches.

\section{CONCLUSIONS}

This paper analyses the heterogeneity in farmers' preferences for the contract of producing certified organic shrimp and in their WTA for the contract's attributes by applying CE approach. The 
hypothetical contracts consist of four attributes which are price premium, premium-payment delay, selling the place and the provision of quality seed. The survey was conducted in the Vietnamese part of the Mekong Delta.

The results show that farmers prefer the contract which offers a higher premium. However, premium-payment delay reduces farmers' utility. Further, we found that there is heterogeneity in farmers' preferences for the premium and premium-payment delay. Another important finding is that almost farmers prefer seed provision. Quality seed could help to improve productivity and increase profit. This attribute is more important in the case of low premium and the negative effect of premium-payment delay on farmer's utility. Farmers' preferences for seed provision are also heterogeneous. A part of farmers strongly prefers to receive quality seed from the company, while a small other part wants to buy seed by themselves. Regarding selling place of certified organic shrimp, a group of farmers (about 59 percent) prefers selling their shrimp at the farm over at the company while the other group does not. And the WTA for bringing the certified organic shrimp to sell at the company also differs among farmers in the first group.

Based on the above finding, we suggest that the company should carefully consider contract attributes such as proper premium, seed provision and a suitable place to collect shrimp from farmers to build contracts. On the other hand, a premium-payment delay should be reduced as short as possible, especially try to control it within three months. In addition, a flexible contract should be made to suit the farmers' heterogeneous preferences. Our findings provide useful information for the company to design reasonable contracts with farmers to produce certified organic shrimp as well as for the (local) government to create a better institutional environment for promoting this sustainable production model. Our findings may also be useful for contract design in the aquaculture sector of other developing countries where many companies also want to contract with farmers to supply quality-rich, safe and environmentally friendly products to the international market.

Funding: This study is funded in part by the Can Tho University Improvement Project VN14-P6, supported by a Japanese ODA loan.

Competing Interests: The authors declared that they have no conflict of interests.

Contributors/Acknowledgement: Authors would like to thank farmers for participating in the survey, local government staff, colleges and students of Can Tho University for their all support.

Views and opinions expressed in this study are the views and opinions of the authors, Asian Journal of Agriculture and Rural Development shall not be responsible or answerable for any loss, damage or liability, etc. caused in relation to/arising out of the use of the content.

\section{References}

Abebe, G. K., Bijman, J., Kemp, R., Omta, O., \& Tsegaye, A. (2013). Contract farming configuration: Smallholders' preferences for contract design attributes. Food Policy, 40, 14 24. https://doi.org/10.1016/j.foodpol.2013.01.002.

Blandon, J., Henson, S., \& Islam, T. (2009). Marketing preferences of small-scale farmers in the context of new agrifood systems: a stated choice model. Agribusiness, 25(2), 251-267. https://doi.org/https://doi.org/10.1002/agr.20195.

Broch, S. W., Strange, N., Jacobsen, J. B., \& Wilson, K. A. (2013). Farmers' willingness to provide ecosystem services and effects of their spatial distribution. Ecological Economics, 92, 78 86. https://doi.org/10.1016/j.ecolecon.2011.12.017.

Christensen, T., Pedersen, A. B., Nielsen, H. O., Mørkbak, M. R., Hasler, B., \& Denver, S. (2011). Determinants of farmers, willingness to participate in subsidy schemes for pesticide-free buffer zones - A choice experiment study. Ecological Economics, 70(8), 1558-1564. https://doi.org/10.1016/j.ecolecon.2011.03.021. 
Espinosa-Goded, M., Barreiro-Hurlé, J., \& Ruto, E. (2010). What do farmers want from agrienvironmental scheme design? A choice experiment approach. Journal of Agricultural Economics, 61(2), 259-273. https://doi.org/10.1111/j.1477-9552.2010.00244.x.

FAO (2019). GLOBEFISH Highlights April 2019 ISSUE, with Jan. - Dec. 2018 Statistics - A quarterly update on world seafood markets. Retrieved May 13, 2020, from http://www.fao.org/3/ca5307en/ca5307en.pdf.

Gelaw, F., Speelman, S., \& Van Huylenbroeck, G. (2016). Farmers' marketing preferences in local coffee markets: Evidence from a choice experiment in Ethiopia. Food Policy, 61, 92-102. https://doi.org/10.1016/j.foodpol.2016.02.006.

General statistics office of Vietnam (2016). Production of aquaculture shrimp by province. Retrieved November 12, 2016, from https://www.gso.gov.vn/default_en.aspx?tabid=778.

GIZ (Deutsche Gesellschaft für Internationale Zusammenarbeit GmbH). (2014). Status of smallscale environmentally friendly shrimp ptoduction in Ca Mau Province. Retrieved October 20, 2016, from https://daln.gov.vn/r/files/ICMP-CCCEP/tai_lieu/camau/02---Shrimpbaseline---EN---final.pdf.

Glover, D. J. (1987). Increasing the benefits to smallholders from contract farming: problems for farmers' organizations and policy makers. World Development, 15(4), 441-448. Retrieved from https://doi.org/10.1016/0305-750X(87)90112-4.

Grisolia, J. M., \& Willis, K. (2011). Heterogeneity in Willingness-to-pay for theatre productions: individual specific Willingness-to-pay estimates for theatres, shows and their attributes. Scottish Journal of Political Economy, 58(3), 378-395. https://doi.org/10.1111/j.14679485.2011.00551.x.

Ha, T. T. T., Bush, S. R., Mol, A. P. J., \& Van Dijk, H. (2012). Organic coasts? Regulatory challenges of certifying integrated shrimp-mangrove production systems in Vietnam. Journal of Rural Studies, 28(4), 631-639. https://doi.org/10.1016/j.jrurstud.2012.07.001.

Hensher, D. A., Greene, W. H., \& Rose, J. M. (2006). Deriving willingness-to-pay estimates of travel-time savings from individual-based parameters. Environment and Planning A, 38, 2365-2376. https://doi.org/10.1068/a37395.

Hensher, D. A., Rose, J. M., \& Greene, W. H. (2005). Applied Choice Analysis: A Primer. New York, USA: Cambridge University Press.

Hole, A. R. (2008). Modelling heterogeneity in patients' preferences for the attributes of a general practitioner appointment. Journal of Health Economics, 27(4), 1078-1094. https://doi.org/10.1016/j.jhealeco.2007.11.006

IUCN (2016). Mangroves \& Markets final workshop: results and lessons learned. Retrieved January 15, 2017, from https://www.iucn.org/content/mangroves-markets-final-workshopresults-and-lessons-learned.

Lemeilleur, S., Subervie, J., Presoto, A. E., Souza Piao, R., \& Saes, M. S. M. (2020). Coffee farmers' incentives to comply with sustainability standards. Journal of Agribusiness in Developing and Emerging Economies. Advanced online publication. https://doi.org/10.1108/JADEE-04-2019-0051.

Louviere, J. J., \& Hensher, D. A. (1982). Design and analysis of simulated choice or allocation experiments in travel choice modeling. Transportation Research Record, 890, 11-17.

Louviere, J. J., \& Woodworth, G. (1983). Design and analysis of simulated consumer choice or allocation experiments: An. Journal of Marketing Research, 20(4), 350-367.

Ochieng, D. O., Veettil, P. C., \& Qaim, M. (2017). Farmers' preferences for supermarket contracts in Kenya. Food Policy, 68, 100-111. https://doi.org/10.1016/j.foodpol.2017.01.008.

Rehber, E. (2007). Contract Farming: Theory and Practice (first edit). India: The Icfai University Press.

Schipmann, C., \& Qaim, M. (2011). Supply chain differentiation , contract agriculture , and farmers ' marketing preferences: The case of sweet pepper in Thailand. Food Policy, 36(5), 667677. https://doi.org/10.1016/j.foodpol.2011.07.004. 
Singh, S. (2002). Contracting out solutions : political economy of contract farming in the Indian Punjab. World Development, 30(9), 1621-1638. https://doi.org/10.1016/S0305750X(02)00059-1.

Train, K. (2002). Discrete Choice Methods with Simulation. Cambridge University Press.

Tran, T. H. S., \& Ha, V. H. (2008). The variation of mangrove resources in the Mekong River Delta and orientations for conservation and development. Hue University Journal of Sciences, 48, $135-142$.

Trifković, N. (2014). Certified standards and vertical coordination in aquaculture: The case of pangasius fromVietnam. Aquaculture, 433, 235-246. https://doi.org/10.1016/j.aquaculture.2014.06.010.

Van den Broeck, G., Vlaeminck, P., Raymaekers, K., Vande Velde, K., Vranken, L., \& Maertens, M. (2017). Rice farmers' preferences for fairtrade contracting in Benin: Evidence from a discrete choice experiment. Journal of Cleaner Production, 165, 846-854. https://doi.org/10.1016/j.jclepro.2017.07.128.

Vassalos, M., Hu, W., Woods, T., Schieffer, J., \& Dillon, C. (2016). Risk preferences, transaction costs, and choice of marketing contracts: evidence from a choice experiment with fresh $\begin{array}{llll}\text { vegetable } \quad \text { producers. } & \text { 32(3), }\end{array}$ https://doi.org/https://doi.org/10.1002/agr.21450/.

Villanueva, A. J., Rodríguez-Entrena, M., Arriaza, M., \& Gómez-Limón, J. A. (2017). Heterogeneity of farmers' preferences towards agri-environmental schemes across different agricultural subsystems. Journal of Environmental Planning and Management, 60(4), 684707. https://doi.org/10.1080/09640568.2016.1168289. 